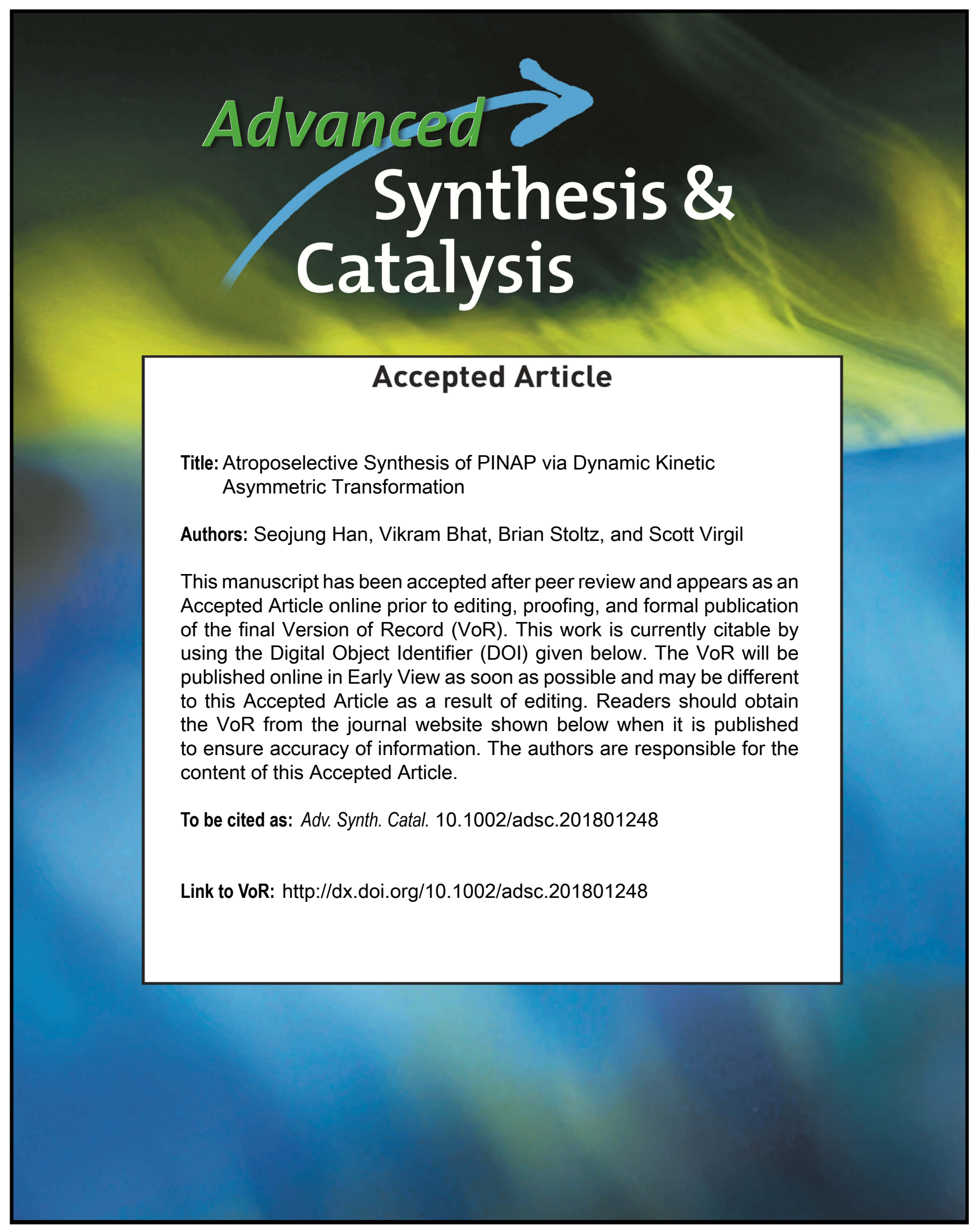


DOI: 10.1002/adsc.201((will be filled in by the editorial staff))

\title{
Atroposelective Synthesis of PINAP via Dynamic Kinetic Asymmetric Transformation
}

\author{
Seo-Jung Han, ${ }^{\text {a,b }}$ Vikram Bhat, ${ }^{\text {a,c }}$ Brian M. Stoltz, ${ }^{* a}$ and Scott C. Virgil*a
}

a The Warren and Katharine Schlinger Laboratory for Chemistry and Chemical Engineering, Division of Chemistry and Chemical Engineering, California Institute of Technology, 1200 East California Boulevard, MC 101-20, Pasadena, California 91125, United States

E-mail: stoltz@caltech.edu and svirgil@caltech.edu

b Chemical Kinomics Research Center, Korea Institute of Science and Technology (KIST), 5, Hwarangro 14-gil, Seongbuk-gu, Seoul, 02792, Republic of Korea

c Abbvie, Inc., $1 \mathrm{~N}$ Waukegan Road, North Chicago, IL 60064, United States

Received: ((will be filled in by the editorial staff))

Supporting information for this article is available on the WWW under http://dx.doi.org/10.1002/adsc.201\#\#\#\#\#\#.((Please delete if not appropriate))

\begin{abstract}
The atroposelective synthesis of PINAP ligands has been accomplished via a palladium-catalyzed $\mathrm{C}-\mathrm{P}$ coupling process through dynamic kinetic asymmetric transformation. These catalytic conditions allow access to a wide variety of alkoxy- and benzyloxy-substituted PINAP ligands in high enantiomeric excess. The methods described in this communication afford valuable $\mathrm{P}, \mathrm{N}$ ligands in good yields and high enantioselectivity using low catalyst loading.
\end{abstract}

Keywords: PINAP; Dynamic kinetic asymmetric transformation; Atroposelective synthesis; P,N ligands

The unique properties of the axially chiral P,N ligand QUINAP (1) have been employed widely for various transition metal catalyzed asymmetric reactions. ${ }^{[1]}$ Thus, approaches to the synthesis of QUINAP ligands in high enantiomeric purity have been developed. ${ }^{[2,3]}$ In 2013, our laboratories explored the palladium-catalyzed atroposelective synthesis of QUINAP and its derivatives via kinetic resolution and dynamic kinetic asymmetric transformation. ${ }^{[4]}$ With a robust method for the synthesis of chiral QUINAP in hand, we turned our attention to the architecturally related PINAP ligands (2). ${ }^{[5]}$ PINAP ligands (2a and $2 \mathbf{b}$ ), which possess analogous ligation reactivity to QUINAP, were first developed by the Carreira group in 2004. ${ }^{[6]}$ Carreira and co-workers separated the two atropoisomeric diastereomers through column

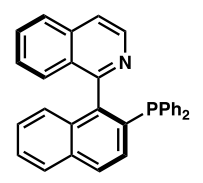

QUINAP (1)

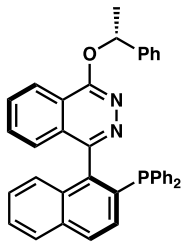

O-PINAP (2a)
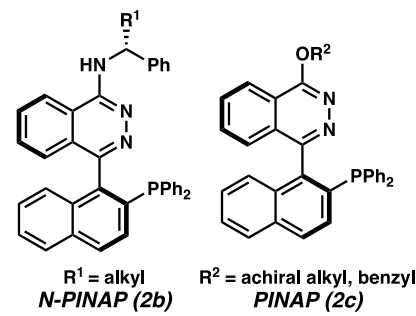

Figure 1. QUINAP (1) and PINAP (2)

chromatography by preparing chiral ether- or aminesubstituted PINAP scaffolds. Herein, we disclose synthetic methods for accessing enantiomerically enriched PINAP ligands via dynamic kinetic asymmetric transformation $(\mathbf{2 a}, \mathbf{2 c})$.

Table 1. Scope of Dynamic Kinetic Asymmetri

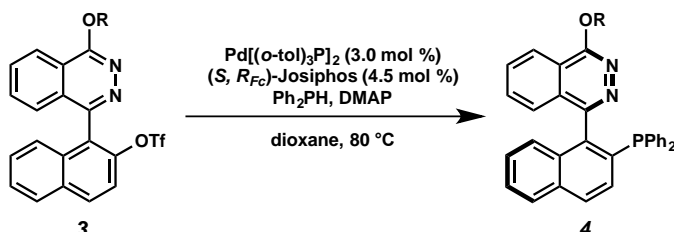

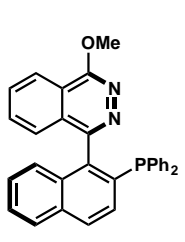

$4 a$

$90 \%$ yield ${ }^{b}, 82 \%$ ee $^{c}$

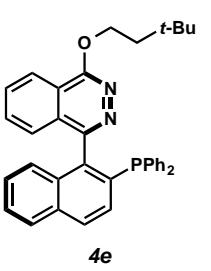

$61 \%$ yield $^{b}, 88 \% e^{c}$

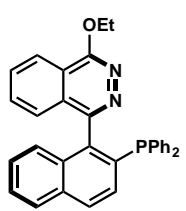

$4 b$

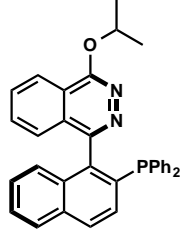

$4 c$

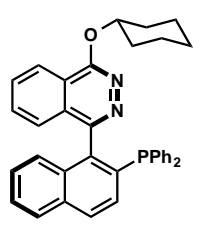

$4 d$

$48 \%$ yield, $71 \%$ ee $\quad 71 \%$ yield , $86 \%$ ee $\quad 80 \%$ yield , $75 \% e^{c}$

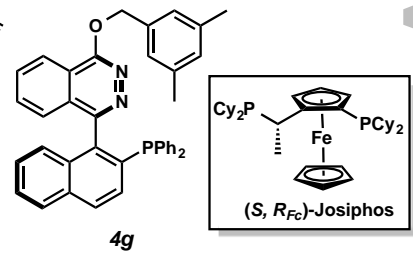

$70 \%$ yield, $60 \%$ ee

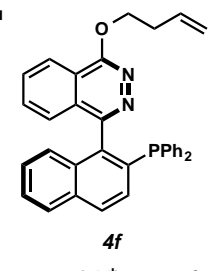

a Reactions performed with 1.0 equiv of triflate $3,4.0$ equiv of DMAP, $3.0 \mathrm{~mol} \%$ of $\mathrm{Pd}\left[(o-\mathrm{tol})_{3} \mathrm{P}\right]_{2}, 4.5 \mathrm{~mol} \%$ of $\left(S, R_{F c}\right)$-Josiphos, 1.05 equiv of 
$\mathrm{Ph}_{2} \mathrm{PH}$ (1.0 $\mathrm{M}$ in dioxane) at $0.20 \mathrm{M}$ in dioxane at $80{ }^{\circ} \mathrm{C}$ in a glovebox. $\mathrm{Ph}_{2} \mathrm{PH}(1.0 \mathrm{M}$ in dioxane) was added over $4 \mathrm{~h}$. b All yields are isolated yields. c Determined by chiral SFC analysis.

Our initial attempts to apply the standard QUINAP dynamic kinetic asymmetric transformation conditions, ${ }^{[4]} 3.0 \mathrm{~mol} \%$ of $\mathrm{Pd}\left[(o \text {-tol })_{3} \mathrm{P}\right]_{2}$ and 4.5 mol \% of $\left(S, R_{F c}\right)$-Josiphos at $80^{\circ} \mathrm{C}$, to aryl triflate $\mathbf{3}$ afforded various alkyl- or benzyl-substituted PINAP ligands (Table 1). Asymmetric C-P couplings via dynamic kinetic asymmetric transformation on substrates incorporating methoxy, ethoxy, and isopropoxy groups furnished the corresponding PINAP ligands in good yields and selectivities (4a, 4b, 4c). Cyclohexyl, 3,3-dimethyl1-butyl, and homoallyl ether groups were also well tolerated under the reaction conditions to give the desired products. (4d, 4e, 4f). Additionally, 3,5dimethyl benzyloxy-substituted PINAP was obtained in good yield and moderate selectivity (4g). Although these initial results were exciting, it was clear that additional optimization was needed to improve the enantioselectivities in the synthesis of these PINAP ligands.

In order to allow more time for the isomerization of the presumed arylpalladium complex before its subsequent phosphination, diphenylphosphine (1.0 M solution in dioxane) was added slowly. ${ }^{[7]}$ In addition, we used pre-stirred $1.0 \mathrm{~mol} \%$ of $\operatorname{Pd}\left[(o-\text { tol })_{3} \mathrm{P}\right]_{2}$ and $1.5 \mathrm{~mol} \%$ of $\left(S, R_{F c}\right)$-Josiphos solutions in dioxane. Interestingly, improved enantioselectivity was observed with reduced palladium and Josiphos ligand loadings ( $1.0 \mathrm{~mol} \%$ and $1.5 \mathrm{~mol} \%$, respectively) (Table 2, entries 1 and 2). We were pleased to find that higher enantioselectivities were obtained at lower temperatures (Table 2, entries 2-4). However, the conversion rate was dramatically diminished at $50{ }^{\circ} \mathrm{C}$ (Table 2, entry 5).

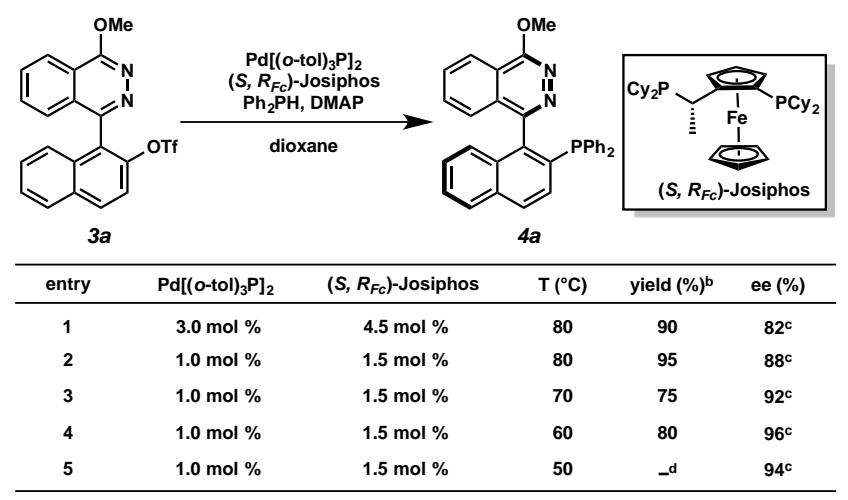

Table 2. Optimization of Reaction Parameters

a Reactions performed with 1.0 equiv of $\mathbf{3 a}, 4.0$ equiv of DMAP, 1.0 mol \% of $\mathrm{Pd}\left[(o-\mathrm{tol})_{3} \mathrm{P}\right]_{2}, 1.5 \mathrm{~mol} \%$ of $\left(S, R_{F C}\right)$-Josiphos, 1.05 equiv of $\mathrm{Ph}_{2} \mathrm{PH}(1.0 \mathrm{M}$ in dioxane) at $0.20 \mathrm{M}$ in dioxane in a glovebox. $\mathrm{Pd}[(o-$ tol $\left.)_{3} \mathrm{P}\right]_{2}$ and $\left(S, R_{F c}\right)$-Josiphos in dioxane were pre-stirred before use. $\mathrm{Ph}_{2} \mathrm{PH}$ (1.0 $\mathrm{M}$ in dioxane) was added over $8 \mathrm{~h}$. b All yields are isolated yields. c Determined by chiral SFC analysis. d $\sim 50 \%$ conversion.

With the optimized conditions in hand, we investigated the substrate scope of the reaction (Table 3). Several alkoxy- and benzyloxy-substituted PINAP ligands were furnished in improved enantioselectivities under the optimized conditions (4a-4h, 57-80\% yields and $82-96 \%$ ee). Ever. PINAP 4g, which had been our worst example under our initial conditions, could now be prepared in $60 \%$ yield and $94 \%$ ee. Applying our optimized condition to a $(R)$-phenylethoxy-substituted substrate, which was previously prepared by the Carreira group by chromatographic separation, generated the corresponding PINAP product in 95\% de (4i). Interestingly, diastereomeric PINAP 2a was produced by our method with lower selectivity using the $(R$, $S_{F c}$ )-Josiphos ligand indicating some balance between substituent and catalyst in the process (e.g., mismatched pair). Thankfully, nearly enantiopure PINAP 2a was obtained after recrystallization. ${ }^{[8]}$ Unfortunately, in the case of $(R)$ - $\alpha$-phenethylamine substituted PINAP, only moderate selectivity was observed (4j). Additionally, application of our conditions to the reaction of triflate $\mathbf{3 a}$ with

Table 3. Scope of Dynamic Kinetic Resolution Under Optimized Conditions 


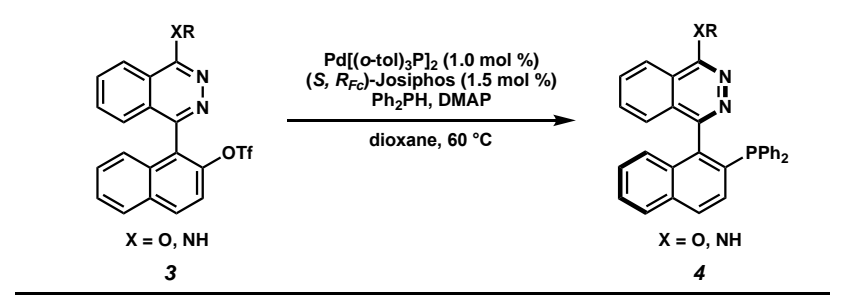

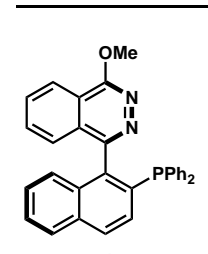

$4 a$

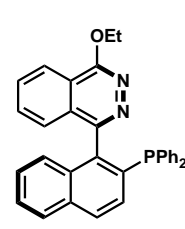

$80 \%$ yield ${ }^{b}, 96 \%$ ee $e^{c} \quad 73 \%$ yield $^{b}, 94 \% e^{c}$

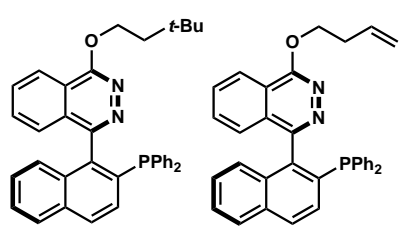

$4 e$

$57 \%$ yield ${ }^{b}, 95 \%$ ee $\quad 67 \%$ yield $^{\mathrm{b}}, 94 \%$ ee<smiles>C[C@H](Oc1nnc(-c2c(-c3ccccc3)ccc3ccccc23)c2ccccc12)c1ccccc1</smiles>

$4 i$

$65 \%$ yield $^{\mathrm{b}}, 95 \%$ de $^{\mathrm{d}, \mathrm{g}} 71 \%$ yield $^{\mathrm{b}}, 88 \%$ de de $^{\mathrm{e}, \mathrm{g}}$ $(57 \%$ yield, $>99 \%$ de
$4 b$

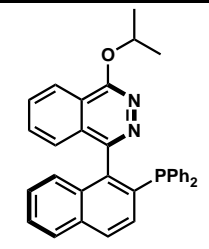

$4 c$

$70 \%$ yield $^{b}, 82 \%$ ee ${ }^{c}$

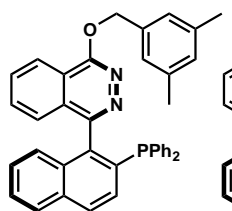

$4 g$
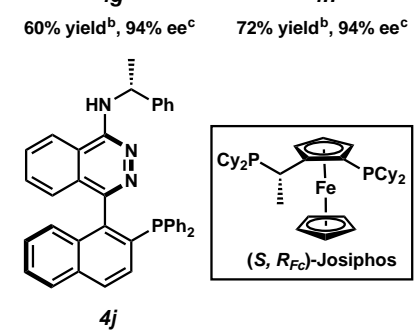

$79 \%$ yield ${ }^{b}, 60 \%$ de $^{g}$

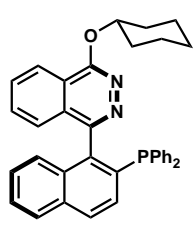

$4 d$ $67 \%$ yield $^{b}, 95 \%$ ee ${ }^{c}$
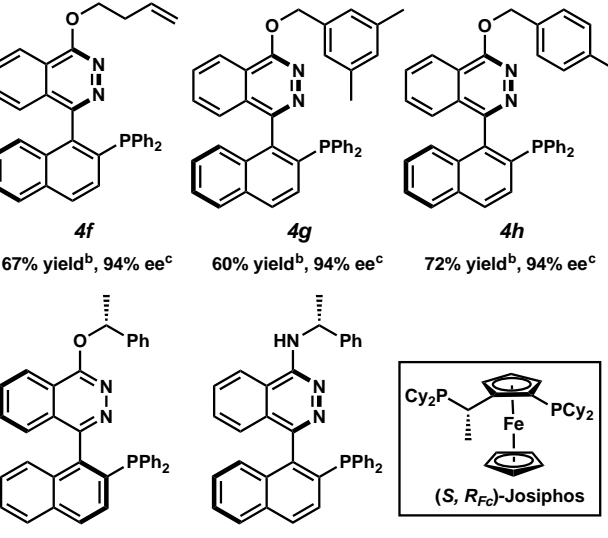

fter recrystallization) a Reactions performed with 1.0 equiv of $3,4.0$ equiv of DMAP, 1.0 mol \% of $\mathrm{Pd}\left[(o-\mathrm{tol})_{3} \mathrm{P}\right]_{2}, 1.5 \mathrm{~mol} \%$ of $\left(S, R_{F c}\right)$-Josiphos, 1.05 equiv of $\mathrm{Ph}_{2} \mathrm{PH}\left(1.0 \mathrm{M}\right.$ in dioxane) at $0.20 \mathrm{M}$ in dioxane at $60{ }^{\circ} \mathrm{C}$ in a glovebox. $\mathrm{Pd}\left[(o \text {-tol })_{3} \mathrm{P}\right]_{2}$ and $\left(S, R_{F c}\right)$-Josiphos in dioxane were pre-stirred before use. $\mathrm{Ph}_{2} \mathrm{PH}$ (1.0 M in dioxane) was added over $8 \mathrm{~h}$. b All yields are isolated yields. c Determined by chiral SFC analysis. d Determined by chiral SFC analysis; SFC conditions: $40 \%$ IPA, $2.5 \mathrm{~mL} / \mathrm{min}$, Chiralpak OD-H column, $\mathrm{tR}(\min )$ : major $=2.26$, minor $=3.12$. e Determined by chiral HPLC. $\mathrm{f}(R$, $S_{F c}$ )-Josiphos was used. g Determined by ${ }^{1} \mathrm{H}$ NMR. h. The absolute stereochemistry of the PINAP ligands were assigned based on the stereochemical outcome of the known PINAP $\mathbf{4 i}, \mathbf{2 a}$, and $\mathbf{4 j}$.

diphenylphosphine oxide or $\left(p-\mathrm{CF}_{3}-\mathrm{C}_{6} \mathrm{H}_{4}\right)_{2} \mathrm{PH}$ proved unsuccessful, and only low yield and selectivities were observed. ${ }^{[9,10]}$

We applied PINAP ligand 4a (96\% ee) to two different reactions (Scheme 1). Copper catalyzed asymmetric phenylacetylene addition to isoquinoline iminium $\mathbf{5}$ with PINAP ligand $\mathbf{4 a}$ afforded propargylamine 6 in $98 \%$ yield and $96 \%$ ee (Scheme 1a). ${ }^{[11,11]}$ In addition, rhodium-catalyzed enantioselective diboration and oxidation of trans- $\beta$ methylstyrene 7 with PINAP 4a produced diol $\mathbf{8}$ in (a)

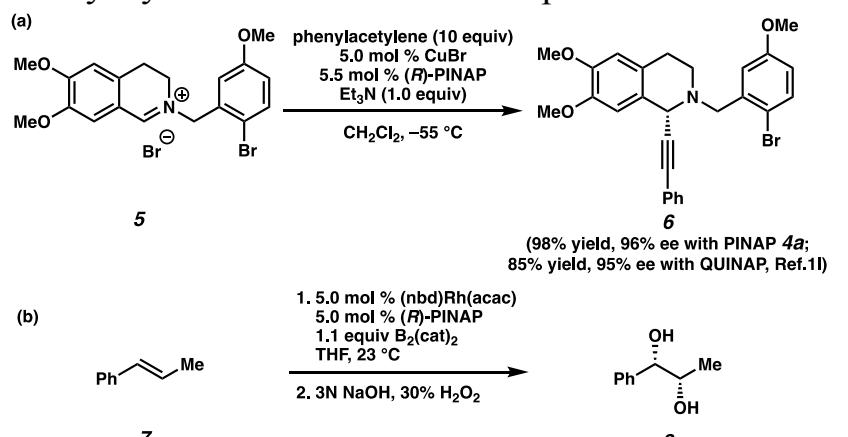

$71 \%$ yield and $88 \%$ ee (Scheme $1 \mathrm{~b}$ ). ${ }^{[1 \mathrm{e}, \mathrm{j}, 12]}$ The enantioselectivities and yields with PINAP ligand 4a are parallel to those with QUINAP 1.

Scheme 1. Applications of PINAP 4a in Catalytic Asymmetric Transformations ${ }^{[13]}$

In conclusion, the atroposelective synthesis of various achiral alkyl- or benzyloxy-substituted PINAP ligands via dynamic kinetic asymmetric transformation has been developed. The asymmetric PINAP ligands formed in this communication are envisioned to be useful in several important asymmetric reactions.

\section{Experimental Section}

(This reaction was performed in a nitrogen-filled glovebox.) $\mathrm{Pd}\left[(o-\text { tol })_{3} \mathrm{P}\right]_{2}(10.8 \mathrm{mg}, 0.0151 \mathrm{mmol})$ and $(S$, $R_{F c}$ )-Josiphos ( $\left.13.7 \mathrm{mg}, 0.0226 \mathrm{mmol}\right)$ in dioxane $(0.302$ $\mathrm{mL}$ ) were pre-stirred in a vial until all the solids were dissolved. To a solution of triflates $3(0.211 \mathrm{mmol}, 1.00$ equiv) in dioxane $(1.06 \mathrm{~mL})$ was added DMAP $(0.844$ mmol, 4.00 equiv) and pre-stirred $\operatorname{Pd}\left[(o-\text { tol })_{3} \mathrm{P}\right]_{2}$ and $(S$, $R_{F c}$ )-Josiphos $(0.05 \mathrm{M}$ in dioxane; $0.00211 \mathrm{mmol}, 0.01$ equiv) at $23{ }^{\circ} \mathrm{C}$. The mixture was placed in a reaction well preheated to $60{ }^{\circ} \mathrm{C}$. A solution of $\mathrm{Ph}_{2} \mathrm{PH}(1.00 \mathrm{M}$ in dioxane; $0.317 \mathrm{mmol}, 1.50$ equiv) was added to the reaction mixture in $20 \mathrm{uL}$ portions every 30 minutes manually. After completion of the addition ( 8 hours), the reaction was stirred for further 7 hours at which point complete consumption of the starting material was observed. The reaction was cooled, removed from the glovebox and dilulted with EtOAc $(1.50 \mathrm{~mL})$ and water $(2.00 \mathrm{~mL})$. The aqueous phase was extracted with EtOAc $(3 \times 1.50 \mathrm{~mL})$. The combined organic phases were washed with brine, dried with $\mathrm{MgSO}_{4}$ and concentrated. The crude material was purified by flash column chromatography on silica gel to afford the corresponding PINAP 4.

\section{Acknowledgements}

The authors wish to thank NIH-NIGMS (R01GM080269), Amgen, the Gordon and Betty Moore Foundation, the Caltech Center for Catalysis and Chemical Synthesis, and Caltech for financial support. S.-J.H. thanks the Fulbright program (Foreign Studer Program, No. 15111120), the Ilju Foundation of Education \& Culture (Pre-doctoral Research Fellowship), and the KIST institutional program (2E28570, 2E28010) for financial support.

\section{References}

[1] a) H. Doucet, E. Fernandez, T. P. Layzell, J. M. Brown, Chem. Eur. J. 1999, 5, 1320-1330; b) J. W. Faller, B. J. Grimmond, Organometallics 2001, 20, 2454-2458; c) K. Maeda, J. M. Brown, Chem. Commun. 2002, 310 311; d) N. Gommermann, C. Koradin, K. Polborn, P. Knochel, Angew. Chem. 2003, 115, 5941-5944; Angew. 
Chem. Int. Ed. 2003, 42, 5763-5766; e) J. B. Morgan, S. P. Miller, J. P. Morken, J. Am. Chem. Soc. 2003, 125, 8702-8703; f) C. Chen, X. Li, S. L. Schreiber, J. Am. Chem. Soc. 2003, 125, 10174-10175; g) E. Daura-Oller, A. M. Segarra, J. M. Poblet, C. Claver, E. Fernández, C. Bo, J. Org. Chem. 2004, 69, 2669-2680; h) A. Black, J. M. Brown, C. Pichon, Chem. Commun. 2005, 52845286; i) N. Gommermann, P. Knochel, Chem. Commun., 2005, 4175-4177, j) S. Trudeau, J. B. Morgan, M. Shrestha, J. P. Morken, J. Org. Chem. 2005, 70, 9538-9544; k) N. Gommermann, P. Knochel, Chem.-Eur. J. 2006, 12, 4380-4392; 1) A. M. Taylor, S. L. Schreiber, Org. Lett. 2006, 8, 143-146; m) X. Li, L. Kong, Y. Gao, X. Wang, Tetrahedron Lett. 2007, 48, 3915-3917; n) T. Miura, M. Yamauchi, A. Kosaka, M. Murakami, Angew. Chem. 2010, 122, 5075-5077; Angew. Chem. Int. Ed. 2010, 49, 4955-4957; o) A. D. Lim, J. A. Codelli, S. E. Reisman, Chem. Sci. 2013, 4, 650-654; p) E. Fernández, P. J. Guiry, K. P. T. Connole, J. M. Brown, J. Org. Chem. 2014, 79, 5391-5400; q) P. Ramírez-López, A. Ros, A. Romero-Arenas, J. Iglesias-

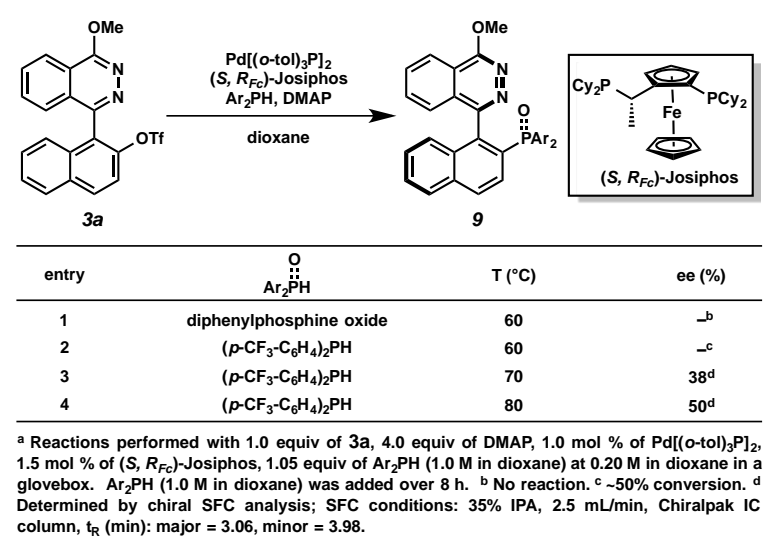

Sigüenza, R. Fernández, J. M. Lassaletta, J. Am. Chem. Soc. 2016, 138, 12053-12056; r) V. Hornillos, A. Ros, P. Ramírez-López, J. Iglesias-Sigüenza, R. Fernández, J. M. Lassaletta, Chem. Commun., 2016, 52, 1412114124; s) V. Bhat, E. R. Welin, X. Guo, B. M. Stoltz, Chem. Rev. 2017, 117, 4528-4561

[2] a) N. W. Alcock, J. M. Brown, D. I. Hulmes, Tetrahedron: Asymmetry 1993, 4, 743-756; b) C. W. Lim, O. Tissot, A. Mattison, M. W. Hooper, J. M. Brown, A. R. Cowley, D. I. Hulmes, A. J. Blacker, Org. Process Res. Dev. 2003, 7, 379-384; c) T. Thaler, F. Geittner, P. Knochel, Synlett 2007, 2655-2658; d) J. Clayden, S. P. Fletcher, J. J. W. McDouall, S. J. M. Rowbottom, J. Am. Chem. Soc. 2009, 131, 5331-5343; e) P. Ramírez-López, A. Ros, B. Estepa, R. Fernández, B. Fiser, E. Gómez-Bengoa, J. M. Lassaletta, ACS Catal. 2016, 6, 3955-3964.

[3] For selective recent examples on the atroposelective syntheses, see: a) S.-C. Zheng, S. Wu, Q. Zhou, L. W. Chung, L. Ye, B. Tan, Nat. Commun. 2017, 8, 15238. b) Q.-J. Yao, S. Zhang, B.-B. Zhan, B.-F. Shi, Angew. Chem., Int. Ed. 2017, 56, 6617-6621. c) L. Zhang, J. Zhang, J. Ma, D.-J. Cheng, B. Tan, J. Am. Chem. Soc. 2017, 139, 1714-1717. d) Y.-B. Wang, S.-C. Zheng, Y.-M. Hu, B. Tan, Nat. Commun. 2017, 8, 15489. e) J. D. Jolliffe, R. J. Armstrong, M. D. Smith, Nat. Chem.
2017, 9, 558-562. f) J. Zheng, W.-J. Cui, C. Zheng, S.L. You, J. Am. Chem. Soc. 2016, 138, 5242-5245. g) C. Yu, H. Huang, X. Li, Y. Zhang, W. Wang, J. Am. Chem. Soc. 2016, 138, 6952-6959. h) R. Miyaji, K. Asano, S. Matsubara, J. Am. Chem. Soc. 2015, 137, 6766-6769. i) A. Berthelot-Bréhier, A. Panossian, F. Colobert, F. R. Leroux, Org. Chem. Front., 2015, 2, 634-644.

[4] V. Bhat, S. Wang, B. M. Stoltz, S. C. Virgil, J. Am. Chem. Soc. 2013, 135, 16829-16832.

[5] For selected recent works on asymmetric reactions with PINAP ligands, see: a) X. Ma, Z. Gu, $R S C A d v$., 2014, 4, 36241-36244; b) S. Zhou, R. Tong, Org. Lett. 2017, 19, 1594-1597; c) W. Fan, W. Yuan, S. Ma, Nat. Commun. 2014, 5, 3884; d) K. Wolosewicz, M. Michalak, J. Adamek, B. Furman, Eur. J. Org. Chem. 2016, 12, 2212-2219.

[6] a) T. F. Knöpfel, P. Aschwanden, T. Ichikawa, T Watanabe, E. M. Carreira, Angew. Chem. 2004, 116, 6097-6099; Angew. Chem., Int. Ed. 2004, 43, 59715973; b) S. Fujimori, T. F. Knöpfel, P. Zarotti, T. Ichikawa, D. Boyall, E. M. Carreira, Bull. Chem. Soc. Jpn. 2007, 80, 1635-1657; c) P. Zarotti, T. F. Knöpfel, P. Aschwanden, E. M. Carreira, ACS Catal., 2012, 2, 1232-1234.

[7] See Ref. 4 for a plausible mechanism of this dynamic kinetic asymmetric transformation.

[8] The crystal was obtained from a gram scale reaction. See supporting information for details.

[9] Attempts to produce PINAP derivatives with diphenylphosphine oxide and $\left(p-\mathrm{CF}_{3}-\mathrm{C}_{6} \mathrm{H}_{4}\right)_{2} \mathrm{PH}$ in high enantioselectivities under our dynamic kinetic asymmetric transformation conditions were unsuccessful.

[10] To demonstrate the scope of our methodology, the enantioselective synthesis of Quinazolinap from triflate 10 was attempted, but our reaction conditions led to poor conversion. Moreover, treatment of triflate 12 with the optimized conditions for PINAP provided the QUINAP ligand in diminished selectivity compared to that with the original reaction conditions ${ }^{4}$.
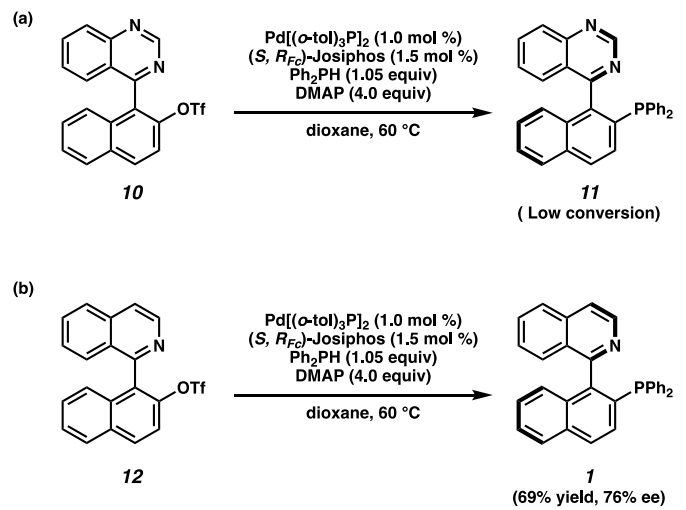

[11] Determined by chiral HPLC analysis: conditions: $10 \%$ IPA $45 \mathrm{~min}, \mathrm{AD}$ column, $\mathrm{t}_{\mathrm{R}}:(\mathrm{min}):$ minor $=10.5 \mathrm{~min}$, major $=18.2 \mathrm{~min}$. All the other spectra data were identical to the reported data. (ref. 11) 
[12] Determined by chiral SFC analysis: conditions: $20 \%$ $\mathrm{MeOH}, 2.5 \mathrm{~mL} / \mathrm{min}, \mathrm{AD}-\mathrm{H}$ column, $\mathrm{t}_{\mathrm{R}}(\mathrm{min})$ : major $=$ $2.46 \mathrm{~min}$, minor $=2.92 \mathrm{~min} ;[\alpha]_{\mathrm{D}}^{25}+38.6$ (c 0.19 , $\mathrm{CHCl}_{3}$ )

[13] 96\% ee (R)-PINAP 4a was used for both applications. 


\section{COMMUNICATION}

Atroposelective Synthesis of PINAP via Dynamic Kinetic Asymmetric Transformation

Adv. Synth. Catal. Year, Volume, Page - Page

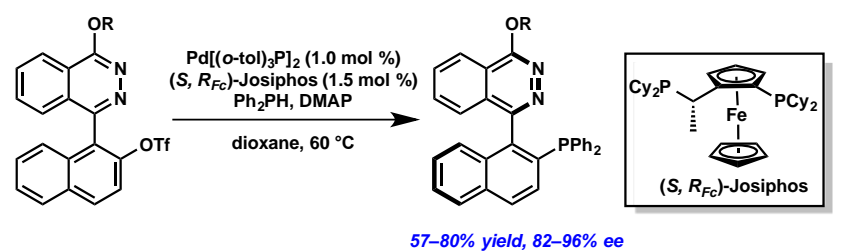

Seo-Jung Han, Vikram Bhat, Brian M. Stoltz,* and Scott C. Virgil* 